Des luttes étudiantes en Europe occidentale (2)

\title{
Notes sur la Théorie critique et sur l'« industrie culturelle »
}

\section{Andrea Cavazzini}

\section{OpenEdition}

\section{Journals}

Édition électronique

URL : http://journals.openedition.org/grm/375

DOI : $10.4000 / g r m .375$

ISSN : 1775-3902

\section{Éditeur}

Groupe de Recherches Matérialistes

\section{Référence électronique}

Andrea Cavazzini, « Notes sur la Théorie critique et sur l'« industrie culturelle » », Cahiers du GRM [En ligne], 4 | 2013, mis en ligne le 18 décembre 2013, consulté le 22 septembre 2020. URL : http:// journals.openedition.org/grm/375; DOI : https://doi.org/10.4000/grm.375

Ce document a été généré automatiquement le 22 septembre 2020

(C) GRM - Association 


\title{
Notes sur la Théorie critique et sur l'« industrie culturelle »
}

\author{
Andrea Cavazzini
}

L'efficacité littéraire, si elle doit être remarquée, ne peut être le fruit que d'un échange pénétrant de l'action et de l'écriture; dans les tracts, les

brochures, les articles de magazine, sur les affiches, elle doit travailler les formes qui n'ont

l'air de rien, qui correspondent mieux que l'exigeant geste universel du livre au crédit dont elle bénéficie dans les communautés laborieuses.

Walter Benjamin, Sens unique

1 Le point de départ de ces remarques est un décalage qui caractérise une certaine effervescence publicationnelle récente autour de l'Ecole de Francfort ${ }^{1}$. Ce décalage est manifesté de la manière la plus frappante par le fait empirique suivant (lequel est très certainement le fruit du hasard, mais qu'on pourra néanmoins considérer comme un symptôme) : alors que les éditions Allia publient séparément le chapitre de la Dialektik des Aufklärung consacré à la Kulturindustrie, cet aspect spécifique de la "Théorie Critique » que le texte incarne - la critique de l'« industrie culturelle », justement - est rarement étudié par les commentaires et les reconstructions globales qui voient le jour (éditorial) à peu près au même moment. Si le livre de Jean-Marc Durand-Gasselin choisit, fort peu audacieusement, d'indiquer la ligne (et la lignée) représentée par Jürgen Habermas et Axel Honneth comme le terminus ad quem de l'histoire de l'Ecole, la Préface que Paul-Laurent Assoun a écrite pour la réédition de son livre a le mérite de considérer Habermas moins comme un héritier que comme un liquidateur, dont la tentative théorique - centrée sur les virtualités libératrices de l'agir communicationnel, sur la légitimation de la démocratie parlementaire et prolongée par la problématique honnethienne de la reconnaissance intersubjective - équivaut à un refoulement en règle de la confrontation menée par les «pères fondateurs » avec « le sujet en proie à une vérité divisée d'elle-même» (p. 7). Mais P.-L.- Assoun ne semble pas considérer la critique de ce que la Dialektik der Aufklärung ${ }^{2}$ qualifie d'« industrie culturelle » comme 
un point décisif de la problématique de la vérité et du sujet, et de leur division : ce qui finit par déboucher sur une lecture très " philosophique » de la théorie critique, et par escamoter précisément la fonction du matérialisme historique dans l'analyse des conditions de la division du sujet et de la vérité, une fois que ces notions - relevant d'abord du discours psychanalytique - sont transposées dans la sphère de l'histoire et de la politique.

2 Une analyse matérialiste du sujet ne saurait faire l'impasse sur l'incorporation de l'«esprit» et du savoir aux lois structurelles de la production capitaliste, et c'est précisément ce processus d'incorporation que vise la notion de Kulturindustrie. Un autre symptôme révélateur: un certain intérêt actuel à l'égard d'auteurs dont l'objet spécifique est justement le statut social et politique de la production et de la circulation des pratiques et des objets culturels dans le capitalisme avancé - pour ne faire que trois noms : Hans-Magnus Enzensberger, Fredric Jameson, George Steiner - semble pourtant incapable de reconnaître et d'explorer l'influence que la problématique francfortoise de l'industrie culturelle a exercée sur les démarches respectives de ces théoriciens ${ }^{3}$. Ce qui en résulte est, d'une part, une Ecole de Francfort mutilée de tous ses prolongements non strictement philosophiques, et, d'autre part, une critique des formes contemporaines de la culture privée de ses fondements philosophiques - en particulier, de ses rapports avec la question de la division radicale qui affecte le sujet de la praxis historique. Cette double mutilation est d'autant plus fâcheuse qu'elle implique le refoulement des conjonctures dans lesquelles la critique - inspirée par les analyses francfortoises - de l'incorporation capitaliste de la culture a eu directement partie liée avec des pratiques et des mouvances politiques : je fais allusion notamment à la Nuova Sinistra italienne et au mouvement étudiant allemand des années 1960.

3 L'histoire de la réception française de l'Ecole de Francfort n'est pas une histoire particulièrement glorieuse. Elle commence très tardivement, vers la fin des années 1970, alors que les premières appropriations italiennes d'Adorno ont lieu dans les années 1950 (avec la traduction de Minima Moralia, ouvrage considéré d'emblée comme un classique de la critique socio-philosophique de la société capitaliste-avancée). Il s'agit d'appropriations aussi politiques que celles menées par les théoriciens du mouvement étudiant allemand, lesquelles impliquaient souvent des rudes clivages et affrontements avec les "théoriciens critiques» qui se refusaient généralement (à l'exception notable de Marcuse) à assumer le rôle d'orientation pratique que leur pensée aurait pu et dû revêtir. Au contraire, la réception française eut lieu essentiellement par le biais de la philosophie des universités, ce qui correspond à une centralité bien " hexagonale » du discours de l'Université dans la production-diffusion $\mathrm{du}$ discours théorique. Cela peut expliquer la difficulté persistante que rencontre en France la critique de l'industrie culturelle. La force et la persistance de la territorialisation universitaire et des formes traditionnellement bourgeoises de la « haute culture » rendent difficile toute prise de conscience vis-à-vis des dispositifs post-bourgeois de l'assujettissement idéologique, que l'industrie culturelle étudiée par Adorno et Horkheimer incarne et annonce depuis les années 1930. Ce n'est qu'à la fin des années 1970 qu'un Nicos Poulantzas reconnaîtra le rôle hégémonique des mass media dans la nouvelle phase du capitalisme post-bourgeois. Il interroge la restructuration de l'idéologie conservatrice à partir des points suivants: «a) l'irrationalisme propre à l'offensive générale à la fois contre le marxisme et contre le rationalisme des Lumières. Irrationalisme et néo-spiritualisme (...) qui couvrent, en lui 
frayant la voie, un type de rationalité déjà ancien qui tend cette fois à envahir l'ensemble du tissu social : la rationalité instrumentale et la logique technocratique des experts, relativement opposées à celles de la loi et de la volonté générale; b) le néolibéralisme, manifeste dans un discours anti-étatique sous couvert de libération de l'individu des empiètements de l'Etat » :

Bien que les tenants de ce néo-libéralisme se présentent souvent comme fervents d'un "anarcho-capitalisme ", il ne faut pas entendre qu'ils préconisent par là un réel retour, impossible, au capitalisme concurrentiel sauvage: l'Etat continue à revêtir un rôle organique dans la reproduction du capital. Ce qu'ils préconisent en fait c'est le retrait, déjà bien amorcé, des « fonctions sociales » de l'Etat-Providence (crise de l'Etat keynésien) qui furent une conquête importante des masses populaires ; c) l'autoritarisme, à savoir le nouveau discours de la loi et l'ordre, de la sécurité des citoyens, des restrictions nécessaires des abus des libertés démocratiques (voir la Trilatérale), etc. Cette restructuration du contenu du discours dominant correspond à, et même induit et accuse, des modifications considérables des canaux et appareils qui l'élaborent et le diffusent. Le rôle idéologique principal se déplace de l'école, de l'université, de l'édition vers les médias (cfr. R. Debray). Or il est important d'ajouter que ce déplacement renvoie, au sein des circuits étatiques, à un déplacement plus général des procédures de légitimation, des partis politiques à l'administration d'Etat dont ils étaient, par là même, les interlocuteurs privilégiés ${ }^{4}$.

4 Cette reconnaissance est très tardive par rapport à l'essor, déjà bien évident, d'un pouvoir autonome de l'industrie culturelle qui date, en Europe occidentale, au moins des années 1960, de la diffusion de la radiotélévision, de la presse " populaire » et de la publicité comme phénomène omniprésent. La campagne contre les éditions Springer menée par les étudiants allemands précède 1968, et, selon Hans-Magnus Enzensberger, analysant le modèle-Springer de la presse populaire et le paradigme que représente le Bild-Zeitung, tant le geste critique du "démasquage » idéologique traditionnel que les campagnes ouvertement militantes constituaient des formes de lutte inadéquates vis-àvis du fonctionnement réel de l'industrie culturelle de l'Allemagne capitaliste-avancée :

Si la critique théorique du Bild-Zeitung enfonçait des portes ouvertes, la critique pratique, avec ses manifestations et ses blocus, ses mélanges incendiaires et ses cocktails Molotov (...) a commis l'erreur de prendre le Bild pour un organe de combat fasciste. Or, il suffit de relire ses fameux appels à la chasse à l'homme (et à l'amour du prochain), au lynchage (et à la protection des animaux), pour comprendre combien cette interprétation était fausse (...). Ce journal n'est pas fasciste, parce qu'il n'a pas été créé pour mobiliser les masses, mais au contraire pour les déshabituer de tout mouvement (...). Ce qui distingue [les organes politiques national-socialistes] du Bild, c'est qu'ils ont un message - si méprisable soit-il - à transmettre et que le contenu politique leur importe, si repoussant soit-il. Le message du Bild, au contraire, c'est qu'il n'y a plus de message concevable ; son seul contenu, la liquidation de tout contenu ${ }^{5}$.

6 L'industrie culturelle qui a produit le Bild rend impuissante la critique en tant qu'entreprise d'émancipation par la parole rationnelle :

L'impuissance de la critique est un fait massif, et sa raison évidente. Toute tentative pour faire la lumière au sujet du Bild-Zeitung est vaine, parce qu'il n'y a rien à dire sur lui que tout le monde ne sache déjà. Cette constatation vaut non seulement pour ceux qui font le journal, mais principalement pour ses lecteurs, dont le cynisme n'est pas moindre. Leur minorité, dont ils sont eux-mêmes responsables, n'attend aucune émancipation, car elle est parfaitement consciente. Ce sentiment de culpabilité, parce qu'il est déjà élucidé, condamne toute élucidation à l'échec ${ }^{6}$. 
7 L'obsolescence de gestes tels que «faire la lumière » et «élucider » renvoie évidemment à l'impuissance du projet critique des Lumières lui-même, de l'Aufklärung dont la liberté de la presse et la formation d'un vaste espace public de circulation des opinions représentent presque des paradigmes. Le Bild, ce sommet de l'industrie culturelle, a détourné ces deux projets en affirmation de l'insignifiance généralisée :

On ne lit pas le Bild bien qu'il ne parle de rien, mais pour cela même : parce qu'il a largué le contenu par-dessus bord, ne connaît ni passé ni avenir et met en pièces toutes les catégories historiques, morales et politiques. Non pas bien que, mais parce que: parce qu'il menace, bêtifie, fait peur, débite des obscénités, sème la haine, parle pour ne rien dire, bave, console, manipule, transfigure, ment, fait l'idiot et détruit. C'est précisément cette terreur, immuable et quotidienne, qui procure au lecteur une paradoxale jouissance, commune à tous les intoxiqués et inséparable de l'avilissement consciemment vécu qui lui est lié7.

8 Si l'idéal (habermasien) de l'opinion publique éclairée est neutralisé, un autre principe fondamental de la culture oppositionnelle - l'effet émancipateur de l'esthétique d'avant-garde et de ses traumatismes systématiques - est mis en pièces par l'industrie culturelle : « Le modèle formel du Bild-Zeitung est radicalement moderne, puisqu'il n'est autre que l'œuvre d'art de l'avant-garde. Le Bild a exproprié non seulement les sciences émancipatrices, de la psychanalyse à la théorie critique, mais aussi les arts du XXe siècle » :

Le Bild, c'est la rupture devenue quotidienne avec toute langue et toute forme traditionnelle; c'est le collage, le montage et l'assemblage, l'objet trouvé et l'écriture automatique, le flux de conscience et de l'inconscience, la poésie sans poésie ; c'est la mise en pièces esthétique de l'esthétique, le dépassement de l'art, la somme esthétique de notre civilisation (...). S'adressant aux masses et lu par elles, ce journal, ennemi déclaré de tout ce qui rappelle même de loin l'intelligence, véritable trou noir de la culture, est en même temps le travailleur collectif de l'esthétique, et sa rédaction le James Joyce de la multitude. CEuvre d'art totale, il liquide en les réalisant tous les rêves des mouvements d'avant-garde, du dépassement de la différence entre l'art et la vie à la production collective ${ }^{8}$.

9 Finalement, l'industrie culturelle semble avoir réalisé tous les programmes utopiques conçus à l'intérieur de la sphère culturelle, et visant à trouver pour les arts, le savoir et la parole un usage émancipateur. Le renversement dialectique du processus émancipateur de l'Aufklärung en pratique de domination est un geste typique de la première génération "francfortoise ", celle d'Adorno, Horkheimer et Marcuse, et gouverne tout le dispositif théorique de la Dialektik der Aufklärung. La situation dont le Bild est le symptôme réalise et pervertit, non seulement la critique de la culture dominante, mais également les idéaux égalitaires qui l'inspirent :

Depuis longtemps, la «classe dominante» ne crée plus sa propre culture et ne manifeste aucun besoin d'un produit de ce genre ; l'analphabétisme fonctionnel ne peut d'autre part plus passer pour le privilège des opprimés, mais fait partie de la panoplie normale des oppresseurs eux-mêmes (...). Ainsi, sous son masque grimaçant et grotesque, [le Bild] a réalisé l'utopie depuis longtemps abandonnée d'une société sans classes : il n'offre plus quelque chose à chacun, mais rien à tous ${ }^{9}$.

Cette réalisation pervertie est caractérisée par l'émergence de l'analphabétisme secondaire en tant que phénomène anthropologique investissant la structure de la subjectivité en régime capitaliste avancé : "[L'analphabète secondaire] n'est pas à plaindre : la perte de mémoire dont il est affligé ne le fait point souffrir. Son manque d'obstination lui rend les choses faciles, il apprécie de ne pouvoir jamais se concentrer et tient pour avantages son ignorance et son incompréhension de tout ce qui lui arrive. 
Disponible et capable de s'adapter, il jouit d'une grande capacité d'arriver à ses fins. Aussi n'avons-nous pas besoin de nous faire du souci pour lui »:

Ce qui contribue au bien-être de l'analphabète secondaire, c'est qu'il ne soupçonne pas du tout qu'il est un analphabète secondaire: il se considère comme informé, sait déchiffrer modes d'emploi, pictogrammes et chèques, et le milieu dans lequel il se meut le protège, comme une cloison étanche, de tout désaveu de sa conscience (...). L'analphabète secondaire est le produit d'une nouvelle phase de l'industrialisation. Une économie, dont le problème n'est plus la production mais la vente, peut ne plus avoir besoin d'une armée de réserve disciplinée; il lui faut des consommateurs qualifiés. L'entraînement sévère, auquel le travailleur du secteur de la production et l'employé de bureau étaient soumis, devient également superflu et l'alphabétisation une entrave (...) Notre technologie a développé, en même temps que les données du problème, la solution adéquate $:$ la télévision, média idéal pour l'analphabète secondaire ${ }^{10}$. capitalisme occidental des années 1980 relève d'une conjoncture différente de celle qui avait assisté à l'élaboration des analyses d'Adorno et Horkheimer dans les années 1940 et à leurs effets politiques entre les années 1950 et 1960. Le déploiement accompli des pouvoirs de l'industrie culturelle, non seulement rend gravement insuffisante toute position critique qui n'aurait pas médité la leçon de l'Ecole de Francfort, mais demande également une critique et une révision des positions propres à celle-ci. Le triomphe du Bild-Zeitung neutralise non seulement l'Aufklärung de l'opinion publique habermassienne, mais aussi sa «dialectique " énoncée par Adorno et Horkheimer, lesquels ne renonçaient guère à la fonction critique, vis-à-vis de l'industrie culturelle, que pouvaient revêtir la «haute culture » et la création esthétique moderniste ou d'avant-garde.

12 C'est l'idée francfortoise d'un noyau irréductible correspondant à une sphère culturelle authentiquement émancipatrice qu'Enzensberger avait critiquée dans les années 1960. C'est pourquoi il proposait de parler d'« industrie du façonnement des esprits » : selon l'écrivain allemand, le nom « industrie culturelle » contribue à entretenir l'illusion que dans cette branche industrielle il $\mathrm{y}$ va toujours de la vie culturelle en tant que sphère autonome de contenus: au contraire, "elle n'en veut rien savoir. Philosophie et musique, art et littérature, ces choses dont après tout elle vit, elle les écarte, les relègue "en bas de page", leur assigne des endroits réservés où elles devront être gardées à vue. Le terme d'industrie culturelle lui sert ainsi à refouler ce dont elle vit » :

La mode, les "stylistes", les conseillers religieux et le tourisme ne sont guère encore reconnus et étudiés comme des formes du façonnement industriel des esprits; de même il y aurait lieu d'abord d'étudier la manière dont la conscience «scientifique» est industriellement inculquée, en prenant pour exemples la nouvelle physique, la psychanalyse, la sociologie, les sondages de l'opinion publique et autres disciplines (...). L'industrialisation de l'enseignement n'a commencé que de nos jours; tandis que nous en sommes encore à discuter d'emplois du temps, de systèmes scolaires, du manque de professeurs et de la pleine utilisation des locaux, déjà se préparent les moyens techniques qui font de tout débat sur la réforme scolaire un anachronisme ${ }^{11}$.

13 Le «façonnement industriel des esprits » est une pratique sui generis qui ne relève plus des distinctions internes à la sphère traditionnelle de la culture, fût-elle « inauthentique » ou manipulée. Cette pratique est gouvernée par des lois propres, qui ne correspondent plus à celles du domaine autonome de la culture tel que la civilisation bourgeoise l'entendait : c'est pourquoi toute démarche visant à opposer aux produits de 
l'industrie culturelle les grandes œuvres de l'esprit soi-disant «pur» ne saurait être pertinente dans la situation capitaliste-avancée :

Comme si la critique culturelle n'était pas elle-même une partie de ce qu'elle critique comme si elle pouvait, de quelque façon que ce soit, s'exprimer sans utiliser l'industrie chargée du façonnement des esprits, ou plutôt sans que celle-ci se serve d'elle ${ }^{12}$.

Le diagnostic d'Enzensberger débouche sur une stratégie politique qui suppose une évaluation relativement optimiste de la situation :

Il ne s'agit pas de rejeter cet appareil industriel dans un geste d'impuissance, mais d'entrer dans son jeu dangereux ${ }^{13}$

La production industrielle des consciences suppose que chaque individu dispose de conscience, jugement, faculté de décision - elle n'a de cesse d'affirmer ce qu'elle nie pratiquement :

Seules se laissent exploiter des forces qui ont une réalité ; pour les domestiquer au service du pouvoir, encore faut-il d'abord les éveiller (...). Le fait qu'elle amène tous les individus à prendre part à la chose commune peut très bien se retourner contre ceux au service de qui la machine fonctionne ${ }^{14}$.

Cette contradiction devrait déboucher sur la préfiguration d'une transformation du statut social de l'intellectuel, appelé à utiliser sa propre incorporation à l'industrie du façonnement des esprits contre les fins de celle-ci. La proposition d'Enzensberger s'inscrit dans les nombreuses critiques de l'Ecole de Francfort - fréquentes tant en Italie que dans le mouvement étudiant allemand - qui visent la tendance propre à la Théorie critique à présenter la société capitaliste-avancée comme un "système » autoréglé et impénétrable contre lequel toute position critique ne saurait qu'assumer une attitude contemplative et extérieure. Enzensberger vise à transformer la critique en praxis, non par l'allégeance habermassienne à la politique libéral-démocrate, mais d'une manière proche, bien que différente, des positions de Hans-Jürgen Krahl et du SDS - par la saisie tactique des occasions de transformation immanentes à la structure sociale. Dans les années 1980, cette stratégie aura été abandonnée par Enzensberger, mais l'idée restera que l'autonomisation de l'industrie culturelle rend impossible de lui opposer des contenus culturels censés être « intacts » et spontanément " antagonistes » alors même que le fonctionnement de la production et de la circulation des formes culturelles a rendu fongible tout contenu déterminé. Les enjeux de la critique de l'industrie culturelle en deviennent plus clairement liés à la question du statut des pratiques intellectuelles et de leur fonction dans les sociétés capitalistes-avancées.

Dans la Dialektik der Aufklärung, l'industrie culturelle présente des traits assez différents du dispositif qu'analyse Enzensberger. Le portrait que dressent Adorno et Horkheimer est marqué, non seulement par l'expérience des premières formes de la société de masse dans l'Allemagne de Weimar et aux Etats-Unis, mais aussi par l'usage des médias de la part des régimes fascistes. Le caractère dominant de l'industrie culturelle est sa tendance à la massification et à l'uniformisation :

La civilisation actuelle confère à tout un air de ressemblance. Le film, la radio et les magazines constituent un système. Chaque secteur est uniformisé et tous le sont les uns par rapport aux autres (...). Des pays totalitaires aux autres pays, les bâtiments administratifs et les centres d'expositions industrielles se ressemblent presque tous par leur décoration ${ }^{15}$.

L'industrie culturelle scelle le processus de dissolution de l'autonomie de l'individu bourgeois « classique » par son incorporation à la société « administrée »:

L'unité évidente entre macrocosme et microcosme présente aux hommes le modèle de leur civilisation : la fausse identité du général et du particulier. Sous le poids des 
monopoles, toute civilisation de masse est identique et l'ossature de son squelette conceptuel fabriqué par ce modèle commence à paraître ${ }^{16}$.

Bien sûr, Adorno et Horkheimer insistent sur le fait que l'industrie culturelle relève du développement capitaliste et de ses stratégies de manipulation des masses :

Le film et la radio n'ont plus besoin de se faire passer pour de l'art. Ils ne sont plus que business : c'est là leur vérité et leur idéologie qu'ils utilisent pour légitimer la camelote qu'ils produisent délibérément. Ils se définissent eux-mêmes comme une industrie et, en publiant le montant des revenus de leurs directeurs généraux, ils font taire tous les doutes sur la nécessité sociale de leurs produits ${ }^{17}$.

16 L'industrie culturelle ne relève pas du développement technologique en tant que tel : «Les parties intéressées expliquent volontiers l'industrie culturelle en termes de technologie. Le fait qu'elle s'adresse à des millions de personnes impose des méthodes de reproduction qui, à leur tour, fournissent en tous lieux des biens standardisés pour satisfaire aux nombreuses demandes identiques » :

Les standards de la production sont prétendument basés sur les besoins des consommateurs : ainsi s'expliquerait la facilité avec laquelle on les accepte. Et, en effet, le cercle de la manipulation et des besoins qui en résultent resserre de plus en plus les mailles du système. Mais ce que l'on ne dit pas, c'est que le terrain sur lequel la technique acquiert son pouvoir sur la société est le pouvoir de ceux qui la dominent économiquement. De nos jours, la rationalité technique est la rationalité de la domination même. Elle est le caractère coercitif de la société aliénée; les autos, les bombes et les films assurent la cohésion du système jusqu'à ce que leur fonction nivellatrice se répercute sur l'injustice même qu'elle a favorisée ${ }^{18}$.

Bien que certaines analyses soient très proches de celles d'Enzensberger, le terminus a quo de la critique de l'industrie culturelle est, pour Adorno et Horkheimer, la forme bourgeoise-classique de la société, que l'évolution du capitalisme a détruit :

Libéral, le téléphone permettait encore à l'abonné de jouer le rôle d'un sujet. Démocratique, la radio transforme tous les participants en auditeurs et les soumet autoritairement aux programmes des différentes stations, qui se ressemblent tous (...). Toute trace de spontanéité chez le public est contrôlée par des chasseurs de talents, des compétitions en studio, des manifestations de tout genre sélectionnées par des professionnels ${ }^{19}$.

Mais il faut éviter d'attribuer à la Dialektik der Aufklärung une position nostalgiqueconservatrice vis-à-vis de la phase bourgeoise des sociétés modernes - et ce, bien que le diagnostic pessimiste de Max Weber à propos des difficultés que rencontre la formation de la personnalité à l'époque du capitalisme pleinement déployé représente sans doute un élément important dans la généalogie de la Théorie Critique. Il n'en reste pas moins que l'industrie culturelle est critiquée moins au nom de l'ordre social et des autonomies individuelles de l'âge bourgeois - destinés depuis toujours, selon Adorno et Horkheimer, à être détruits par le développement capitaliste - que de la fonction oppositionnelle des pratiques esthétiques propres à la haute culture moderniste :

La technologie de l'industrie culturelle n'a abouti qu'à la standardisation et à la production en série, sacrifiant tout ce qui faisait la différence entre la logique de l'œuvre et celle du système social ${ }^{20}$.

18 Le processus d'uniformisation correspond à l'affirmation du système social comme identité absolue dans laquelle toute particularité dissonante disparaît; alors que certaines pratiques esthétiques - la « logique de l'œuvre » - représentent et incarnent cette tension entre la fausse totalité de l'ordre social fondé sur la domination et l'irréductibilité du particulier indocile. Mais c'est précisément cette dissonance que l'industrie culturelle tend à effacer en soumettant les formes de la création culturelle à 
un processus d'identification qui leur impose le sceau de la conformité à la logique sociale :

En s'émancipant, le détail devint rebelle et, du romantisme à l'expressionnisme, il s'affirma comme le véhicule de la révolte contre l'organisation. Dans la musique, l'effet harmonique isolé avait aboli la conscience de la totalité formelle; dans la peinture, une couleur fut privilégiée au détriment de l'ensemble de la composition picturale; dans le roman, la profondeur psychologique devint plus importante que sa structure. L'industrie culturelle, en tant que totalité, a mis fin à tout cela. Ne connaissant plus rien en dehors des effets, elle brise leur insubordination et les soumet à la formule qui prend la place de l'œuvre ${ }^{21}$.

19 L'industrie culturelle réaffirme une fausse harmonie entre l'universel et le particulier, entre la totalité et le fragment; mais cette harmonie n'est que l'emprise de la logique totalitaire du social. La tension entre «le produit fini et la vie quotidienne» (p. 137) disparaît, et les produits de la culture sont assujettis au critère du «naturel » et du "spontané", lequel est en réalité le triomphe d'un ordre social redevenu «seconde nature ». La standardisation des produits esthétiques implique de privilégier leur conformité à l'unité et à l'uniformité d'un «style " supposé «naturel » et «harmonieux» contre l'expérimentation systématique de la dissonance et de la déchirure de toute " totalité harmonieuse » - expérimentation qui réalise la fonction de négativité propre à l'œuvre d'art: "Les grands artistes n'ont jamais été ceux qui incarnaient le style le plus pur et le plus parfait, mais ceux qui, dans leurs œuvres, utilisèrent le style pour se durcir eux-mêmes contre l'expression chaotique de la souffrance comme vérité négative »:

Le moment qui, dans l'œuvre d'art, lui permet de transcender la réalité, est en effet inséparable du style ; il ne consiste cependant pas en la réalisation d'une harmonie, d'une unité problématique entre la forme et le contenu, entre l'extérieur et l'intérieur, entre l'individu et la société, mais dans les traits où affleure la contradiction, dans l'échec nécessaire de l'effort passionné vers l'identité. Au lieu de s'exposer à cet échec dans lequel le style de la grande œuvre d'art s'est toujours nié, l'œuvre médiocre s'en est toujours tenue à sa similitude avec d'autres, à un succédané d'identitéé

Si le grand art exprime la souffrance du particulier non-réconcilié, écrasé par l'emprise de l'Identité à soi-même du système social, les produits de l'industrie culturelle confirment l'homogénéité essentielle de la structure de la société et l'insignifiance en elle du particulier, "en subordonnant de la même façon tous les secteurs de la production intellectuelle, à cette fin unique : marquer les sens des hommes de leur sortie de l'usine, le soir, jusqu'à leur arrivée à l'horloge de pointage, le lendemain matin, du sceau du travail à la chaîne $»^{23}$.

21 Ce qui fait problème dans ces analyses, et qui en constitue la limite principale, est moins la tendance à penser l'industrie culturelle à partir de la liquidation qu'elle opère des formes de la civilisation bourgeoise - une stratégie analytique qui correspondait assez bien à la conjoncture dans laquelle écrivaient Adorno et Horkheimer - que le rôle rédempteur assigné à un " grand art » capable d'exprimer la négativité non-réconciliée. Cette position revient à attribuer une fonction critique immanente aux œuvres du haut modernisme - Kafka, Schönberg ou Beckett - et, dans les débats internes à la gauche intellectuelle en Italie et en Allemagne dans les années 1960 et 1970, elle sera opposée tant à la politisation directe de l'art et de la littérature (Brecht) qu'à la récupération " socialiste » de la grande culture bourgeoise (Lukács). Or si les analyses de l'industrie culturelle proposées par Enzensberger dans les années $1980^{24}$ sont pertinentes, force est 
de conclure que l'idée d'un «salut par l'esthétique » (ou par la culture) est devenue en tant que telle radicalement insuffisante. Ce qui impose l'urgence d'essayer de situer plus précisément la fonction de l'esthétique et du culturel dans les sociétés contemporaines.

La théorie du postmodernisme comme "logique culturelle du capitalisme tardif " proposée par Fredric Jameson dans les années 1990 constitue une tentative systématique d'actualiser la critique de l'industrie culturelle et de saisir les changements structurels dans les fonctions de la sphère culturelle. Cette théorie se présente d'abord comme une théorie de l'obsolescence du modernisme vis-à-vis d'une extension maximale du domaine de la « culture» :

Un des indices les plus importants pour suivre la piste du postmoderne pourrait bien être le sort de la culture : une immense dilatation de sa sphère (la sphère des marchandises), une acculturation du Réel immense et historiquement originale, un grand saut dans ce que Benjamin appelait « l'esthétisation » de la réalitée 25.

La culturalisation du réel correspond à une incorporation directe du culturel au capitalisme :

Dans la culture postmoderne, la «culture» est devenue un produit à part entière (...) : le modernisme constituait encore, au minimum et tendanciellement, une critique de la marchandise et une tentative pour qu'elle se transcende. Le postmodernisme est la consommation de la pure marchandisation comme processus $^{26}$.

Le modernisme et le postmodernisme représentent deux "logiques» différentes du système des pratiques culturelles; ces deux logiques sont incarnées par des courants esthétiques et théoriques spécifiques :

L'expressionnisme abstrait en peinture, l'existentialisme en philosophie, les formes ultimes de la représentation dans le roman, les films des grands auteurs, l'école moderniste en poésie (...), sont aujourd'hui perçus comme l'extraordinaire fleuraison d'un élan haut moderniste ${ }^{27}$.

En architecture, Jameson mentionne les cas de Frank Lloyd Wright, Le Corbusier et Mies Van der Rohe; l'opposition à ces figures a marqué l'essor du postmodernisme comme « populisme urbanistique» :

Le haut modernisme se voit ainsi attribuer la destruction du tissu urbain traditionnel et de sa vieille culture de quartier (disjonction radicale du nouvel immeuble, haut moderniste et utopique, de son contexte environnant) (...). Assez logiquement, le postmodernisme en architecture va alors se présenter comme une sorte de populisme esthétique ${ }^{28}$.

23 La critique de l'élitisme et de l'utopisme autoritaire du modernisme architectural est l'emblème de la tendance postmoderne à dissoudre la tension entre la sphère des formes culturelles et la vie quotidienne, tension qu'Adorno et Horkheimer considéraient comme une expression de la négativité non-réconciliée vis-à-vis d'une société soumise aux impératifs de la production capitaliste: le postmodernisme représente «l'effacement de la vieille opposition (essentiellement moderniste) entre la grande Culture et la culture dite commerciale, la culture de masse, effacement marqué par l'émergence de nouveaux types de textes imprégnés des formes, catégories et contenus de cette industrie culturelle dénoncée avec tant de passion par tous les idéologues du moderne, de Leavis et la nouvelle critique américaine (New Criticism) jusqu'à Adorno et l'Ecole de Francfort » :

En fait, les postmodernismes ont précisément été fascinés par ce paysage " dégradé » de la pacotille et du kitsch : la culture des séries TV et du Reader's Digest, la publicité et les motels, les spectacles de second ordre et les films hollywoodiens 
de série $\mathrm{B}$, la soi-disant para-littérature avec ses romans de gare en format poche et ses genres spécifiques - policier, science-fiction, fantasy, gothique, roman d'amour ou biographie populaire -, matériaux que les postmodernistes ne se contentent plus de « citer ", comme un Joyce ou un Mahler ont pu le faire, mais qu'ils incorporent à leur substance même ${ }^{29}$.

Jameson affirme que la différence fondamentale entre modernisme et postmodernisme repose moins sur des contenus spécifiques que sur la «transformation de la sphère même de la culture dans la société contemporaine » (p. 38). Historiquement, l'essor du postmodernisme relève de l'épuisement de la fonction critique et «traumatique » de l'esthétique et de la culture modernistes :

C'est la position sociale de cet ancien modernisme ou, plus exactement, son violent rejet, sa répudiation passionnée par la bourgeoisie victorienne et post-victorienne qui percevait les formes et l'éthos de ce mouvement comme, selon le cas, laids, dissonants, obscurs, scandaleux, immoraux ou subversifs, et, d'une façon générale, comme "anti-sociaux ». Certes, une mutation de la sphère culturelle a rendu archaïques de telles attitudes. Non seulement Picasso et Joyce ne sont plus laids mais ils nous paraissent aujourd'hui, dans l'ensemble, plutôt « réalistes » et c'est là le résultat d'une institutionnalisation académique et d'une canonisation du mouvement moderne en général que l'on peut faire remonter à la fin des années cinquante ${ }^{30}$.

Plus profondément, la «canonisation» du modernisme et de l'avant-garde, leur incorporation au "sens commun" et à la vie quotidienne, ont représenté une incorporation à l'industrie culturelle dans la phase post-bourgeoise des sociétés capitalistes. En 1977, dans une Préface écrite pour la réédition d'une anthologie de textes surréalistes qu'il avait dirigée en 1958, le critique italien Franco Fortini attirait l'attention sur la récupération des transgressions surréalistes par la société capitaliste :

Les surréalistes annonçaient la fin de la littérature, l'écriture automatique, l'humour noir, la tout-puissance du rêve, la force libératrice de l'érotisme et du désir, la beauté convulsive. Tout ce qui, aujourd'hui, est à la portée de tous les kiosques de journaux et de tous les téléviseurs ; mais qui fait aussi, avec de minces variations, l'objet des méditations d'avant-gardes morales et politiques et de séminaires universitaires qui regorgent de bibliographies (...). Les démarches fondamentales du Surréalisme (avec celles qu'expérimentèrent les autres avantgardes) ont imprégné l'expérience soi-disant quotidienne à tel point qu'il faut les considérer comme la seule forme qui correspond d'une manière réellement cohérente à la mutation technologique de notre siècle ${ }^{31}$.

Fortini insiste sur l'homogénéité entre l'esthétique des avant-gardes et l'expérience subjective dans les sociétés capitalistes-avancées : "La "vérité” du monde technologisé (des produits, des profits et des marchandises) ne consiste pas - c'est très clair aujourd'hui - dans la massification scientiste que redoutaient les penseurs et les utopistes de la première moitié du XXème siècle, mais dans son contraire, dans l'onirisme et l'immédiateté, lesquels ont été érigés en principes éthico-politiques au fur et à mesure qu'ils pénétraient dans la perception spatio-temporelle de la vie quotidienne $»$ :

L'industrie des communications et des consciences a offert les modèles de l'art et de la littérature d'avant-garde au consommateur indifférencié ; par-là, elle a introduit dans les existences les moins visiblement habitées par les contradictions de la société capitaliste une tension polaire et insoluble (parce que sans médiation) entre une image de liberté-bonheur-plaisir et une image de nécessité-souffranceprestation. Le Surréalisme diffus et vulgarisé ne revêt pas la fonction qu'Adorno voulait reconnaître dans l'avant-garde d'un Kafka ou d'un Beckett, à savoir, celle de témoigner du scandale et par conséquent de répéter une promesse de bonheur inassouvie. Il agit au contraire comme un multiplicateur de désirs et besoins 
qualitativement identiques à ceux que le système de la production est prêt à satisfaire $^{32}$.

Si, entre les années 1960 et les années 1970, la culture moderniste cesse de revêtir la fonction critico-négative préconisée par Adorno et Horkheimer et devient un élément de la société capitaliste et de ses institutions, le postmodernisme assume ouvertement le scandale de l'impossibilité du scandale par l'acceptation franche et complète de l'homogénéité essentielle entre l'institutionnalisation des outrances et la marchandisation définitive de la sphère culturelle :

La production esthétique s'est aujourd'hui intégrée à la production de marchandises en général: la pression économique, qui pousse à produire frénétiquement des flots toujours renouvelés de biens toujours plus nouveaux en apparence (des vêtements aux avions) à un rythme de remplacement toujours plus rapide, assigne aujourd'hui à l'expérimentation et à l'innovation esthétiques une position et une fonction structurelles toujours plus essentielles ${ }^{33}$.

Autrement dit, le postmodernisme scelle la fin de la fonction critico-utopique de l'art, laquelle, dans les pratiques esthétiques modernistes, se déclinait directement comme conscience persistante du non-identique: "Seule une sociologie (...) comme celle de Weber, qui aurait continué de s'attacher à mesurer l'extraordinaire impact du capitalisme sur les cultures jusqu'ici traditionnelles, à évaluer les dégâts sociaux et psychiques causés à des formes anciennes (...) de la vie et de la perception (...) offrirait un cadre adéquat pour repenser le "modernisme" aujourd'hui » :

Les divers modernismes ont constitué des réactions violentes contre la modernisation tout aussi souvent qu'ils ont reproduit ses valeurs et ses tendances dans leur insistance formelle sur la nouveauté et l'innovation, la transformation des formes anciennes, l'iconoclasme thérapeutique et le développement de nouvelles technologies (esthétiques) miraculeuses. Si, par exemple, la modernisation a quelque chose à voir avec le progrès industriel, avec la rationalisation, avec la réorganisation de la production et de l'administration selon des méthodes plus efficaces, avec l'électricité et la chaîne de montage, avec la démocratie parlementaire et les journaux bon marché - alors il nous faudra conclure qu'au moins une branche du modernisme esthétique est anti-moderne et a vu le jour dans une contestation violente ou assourdie de la modernisation ${ }^{34}$.

La «modernisation» est bien entendu indissociable, pour le marxiste Jameson, de l'emprise croissante des rapports de production capitalistes :

La caractéristique la plus profonde et fondamentale que partagent tous les modernismes ne se trouve pas tant dans leur hostilité à une technologie que certains ont vraiment glorifiée (comme les futuristes) mais plutôt dans leur hostilité au marché lui-même. Cette caractéristique possède un caractère central, ce que confirme son inversion dans les divers postmodernismes qui, différents les uns des autres plus furieusement encore que les divers modernismes, partagent tous au moins l'affirmation retentissante du marché proprement dit, quand il ne s'agit pas d'une franche célébration ${ }^{35}$.

Les différents avatars du modernisme - le symbolisme avec ses formes organiques, les avant-gardes organisées comme des groupes politiques ou para-militaires, la fascination vis-à-vis de la technique et de l'accélération, le génie isolé qui poursuit la création de l'Euvre - témoignent d'une tension qui vise constamment la possibilité d'une praxis libérée de l'emprise des rapports sociaux capitalistes :

La majeure partie des « classiques » modernistes se voulaient cependant des figures $\mathrm{du}$ déblocage de l'énergie humaine; la contradiction du modernisme porte sur la façon dont cette valeur universelle de la production humaine ne pouvait parvenir à la figuration que par la signature unique et restreinte du prophète ou visionnaire 
moderniste, la mettant donc progressivement à nouveau hors de portée de tous, sauf des disciples ${ }^{36}$.

L'élitisme moderniste, cible polémique privilégiée du "populisme » postmoderne, représente en effet la rareté de la manifestation de ce qui échappe au système social, une manifestation qui ne peut plus exister que comme expérience privilégiée arrachée à l'identité formelle de la « société administrée » :

La production esthétique offrit la vision utopique d'une production plus humaine de façon générale ; et, dans le monde du stade monopolistique du capitalisme, elle exerça une fascination en offrant l'image d'une transformation utopique de la vie humaine. Joyce fabriqua en solitaire tout un monde dans son appartement à Paris (...) ; mais les êtres humains dans les rues (...) n'avaient aucun sentiment comparable de pouvoir et de maîtrise ou de productivité humaine; rien de la sensation de liberté et d'autonomie qui survient lorsque, comme Joyce, vous êtes capable de prendre vos propres décisions, ou du moins d'y avoir part ${ }^{37}$.

Mais cette fonction de l'esthétique comme concentration de forces humaines virtuellement libérées relève d'une conjoncture sociale et historique déterminée, dont le modernisme représente moins l'expression passive qu'une forme spécifique d'intervention dans la situation qu'elle définit : «L'art moderne (...) tira son pouvoir et ses possibilités du fait d'être une sorte de bras mort dans le fleuve et de représenter une survivance archaïque au sein d'une économie modernisatrice : il glorifia, célébra et dramatisa les anciennes formes de production individuelle que le nouveau mode de production était, ailleurs, sur le point de remplacer et d'effacer $»$ :

En tant que forme de production, le modernisme (Grands Artistes, et producteurs, compris) émet donc un message qui a peu à voir avec le contenu des œuvres individuelles: c'est l'esthétique comme pure autonomie, comme les satisfactions d'un artisanat transfiguré. Il faut donc considérer que le modernisme correspond tout particulièrement à un moment inégal de développement social, à ce que Ernst Bloch appelait la «simultanéité du non-simultané », "le synchronisme du nonsynchrone » (Gleichzeitigkeit des Ungleichzeitig) : la coexistence de réalités issues de moments radicalement différents de l'histoire - les artisanats côte à côte avec les grands cartels, les champs des paysans avec les usines de Krupp ou, au loin, les usines Ford ${ }^{38}$.

Autrement dit, le non-identique que le modernisme exprime par ses expérimentations formelles traumatiques correspond à l'inscription des pratiques esthétiques dans le non-identique d'une structure sociale clivée. Selon Jameson, le postmodernisme traduit et exprime la fin de ce clivage et sa substitution par la logique sociale de l'Identité :

Il faut définir le postmoderne comme une situation où la survivance, le résidu, le rescapé ou l'archaïque a finalement été balayé sans laisser de trace. Le passé luimême a donc disparu dans le postmoderne (...) ; la nature a été victorieusement effacée, en même temps que les paysans, le commerce petit bourgeois, l'artisanat, les aristocraties féodales et les bureaucraties impériales. Notre condition est modernisée de façon plus homogène ; l'embarras des non-simultanéités (...) ne nous encombre plus. Tout est maintenant à la même heure sur la grande horloge du développement et de la rationalisation (du moins dans la perspective de «l'Occident ») $)^{39}$.

Le passé culturel devient une présence stérile : il n'existe plus que comme marchandise, monument ou objet de la recherche savante spécialisée. Selon un autre auteur profondément influencé par l'Ecole de Francfort, cette neutralisation des pratiques culturelles, leur isolement et stérilisation vis-à-vis de l'existence individuelle et sociale, correspond à la généralisation d'un modèle «nord-américain » de rapport à la culture : «[Le] sens instinctif de l'organisation tangible qui inspire les réalisations américaines sur le plan politique comme dans le domaine industriel et technique (...) a conduit au 
développement de la culture comme profession, comme spécialisation. Le terme mordant d'Adorno est celui de Kulturproduktion, par quoi il entend l'application aux valeurs et incarnations culturelles (...) des pratiques de fabrication et de conditionnement. La "culture", les arts, la littérature peuvent bien être hissés sur un piédestal, monumentalisés. Mais la phénoménologie qui en résulte réfléchit aussitôt (...) les idéaux d'efficacité cruciaux dans l'ethos américain. C'est une "chose qui est là bas", qu'il appartient aux spécialistes (l'universitaire, le conservateur, l'impresario, l'interprète) de faire exister et d'entretenir. Ses interactions avec la communauté dans son ensemble sont de l'ordre de la présentation ostensible, du contrat, plutôt que d'une présence envahissante, anarchique et subversive »:

Peut-être la distinction sera plus parlante ainsi formulée: les principales réalisations de la vie culturelle américaine sont organisées (superbement) plutôt qu' organiques. Tout aussi inévitablement, cette organisation prendra la forme dominante qui est celle de l'évaluation économique. Le culturel (...) fait alors partie de la dynamique d'ensemble de la consommation ostentatoire. Il n'y a pas seulement Kulturproduktion, mais commercialisation compétitive du produit fini. Avant même, ou presque, qu'il n'entre dans la zone désintéressée, quoique toujours problématique, de l'art, le produit esthétique, intellectuel ou littéraire américain est transformé en artefact ${ }^{40}$.

La culture des musées, des instituts, des recherches spécialisées, est le complément de la sphère des médias, du journalisme et du spectacle : par son biais, la " haute culture " et le "grand art "sont neutralisés comme possibilités d'expérience, et incorporés au domaine de l'industrie culturelle. Finalement, les différences entre la « haute culture » et la culture " dégradée » destinée aux " masses » tendent à disparaitre, à se réduire à une différence interne à la logique de la Kulturindustrie $e^{41}$. Cette logique reproduit la distinction entre "haute culture " et "sous-culture " sous la forme du snobisme de masse: les hiérarchies culturelles font retour au cœur de la massification, mais uniquement comme marqueurs d'inégalités sociales, tout en confirmant l'emprise des impératifs du système sur la subjectivité. Les privilèges liés à l'élitisme des formes culturelles survivent, mais leur tension critique vis-à-vis de la société est éteinte : ils n'existent plus que comme signe de la « consommation ostentatoire » et des différents status des consommateurs des marchandises culturelles. Une conséquence majeure de ce phénomène est le caractère régressif de toute lutte en faveur de l'authenticité sublime de la culture ou d'une forme culturelle qui serait porteuse d'une "mission ", d'un effet ou d'un pouvoir libérateurs intrinsèques. Cette situation historique rend problématique le bilan de l'Ecole de Francfort et de son héritage. Si la critique de l'industrie culturelle reste un point de départ essentiel pour toute analyse des dispositifs culturels du capitalisme avancé - ce que démontrent les travaux d'Enzensberger, Fortini, Jameson et Steiner -, la structure actuelle de ces dispositifs, que lesdits travaux prennent pour objet, ne permet plus d'attribuer des capacités « rédemptrices » à des savoirs ou à des formes déterminés. Tout cela a bien entendu des conséquences sur les possibilités et le sens des pratiques intellectuelles aujourd'hui. L'Ecole de Francfort peut nous aider à comprendre qu'aucune pratique n'a aujourd'hui de valeur qu'à condition de penser, et d'incorporer à ses raisons vitales et à ses statuts fondamentaux, son rapport à l'industrie culturelle. En même temps, il faudra aller audelà de la lettre de la Théorie Critique adornienne et refuser toute illusion consistant à croire qu'il suffirait, pour sortir de l'emprise du «façonnement industriel des consciences ", de lire (ou écrire) les bon livres, d'étudier les bons écrivains, les bons philosophes - fussent-ils ceux de l'Ecole de Francfort -, ou de voir les bons films et les 
bonnes pièces, etc. Toute reproposition irréfléchie de la fonction spécifiquement "moderniste" de l'art, de la littérature ou de la théorie risque de se réduire à simulacre - objet d'imitation ou de consommation passive - de gestes, figures, stylèmes et « codes» culturels devenus désormais homogènes à la multiplicité chaotique des productions culturelles. Autrement dit, à une époque où l'industrie culturelle est devenue coextensive à la vie sociale, aucun contenu ne peut plus être porteur d'un effet émancipateur à moins de se soutenir par un travail explicite sur les conditions auxquelles une pratique culturelle peut devenir une expérience effective de libération et de vérité, de vie-dans-la-cohérence. Ce travail correspond à la réintroduction de la division d'avec soi-même que la Théorie Critique de l'Ecole de Francfort suppose au sujet : la division entre l'emprise intime de la logique du système social, dans laquelle chacun baigne et dont il tire les strates immédiates de sa substance subjective, et la tension, également intime, vers une consistance supérieure des paroles et des actions, vers un partage authentique de la vérité et de la connaissance. Mais, de toute évidence, les conditions auxquelles les savoirs et les connaissances pourraient être incorporés au processus de cette division précèdent, et excédent, tout savoir. Ce passage de Fortini me semble exprimer très clairement ce qui est en jeu dans cet excès :

Qu'est-ce qui nous fait sortir [de l'industrie culturelle]? C'est l'action politique, entendue comme décision en faveur de comportements non-individuels, dont les raisons ne sont pas à chercher ni à vérifier dans et par le savoir ou la culture, car elles se fondent - au moins au départ - sur le déjà-connu, sur ce qui est en nous ou hors de nous (pour moi, c'est la même chose). Et ce «quelque chose » que nous connaissons déjà, nous vient de notre expérience vitale. C'est un "quelque chose » dans lequel la souffrance pour l'injustice et l'oppression subies hier est nouée au souvenir de ce que nous avons appris et su depuis toujours. Ce « nouage » est notre savoir, différent de celui qui vient «après» (...), lequel peut devenir «chair et sang » à condition que ce moment premier ait eu lieu (...). Et quelle est l'opération politique par excellence? Trouver ses camarades, se reconnaitre les uns les autres, s'unir, décider de faire quelque chose, ne fût-ce qu'une rencontre ou une conversation (...). Les problèmes des livres, du savoir, se posent immédiatement après ceux que Mao associe à l'enquête, à la recherche menée pour comprendre le monde dans lequel nous voulons agir et que nous voulons modifier ${ }^{42}$

\section{NOTES}

1. En témoignent en particulier les ouvrages suivants, récemment publiés ou réédités: P.-L. Assoun, L'Ecole de Francfort, Paris, PUF, 2012 (réédition, avec une nouvelle préface, d'un ouvrage paru en 2001 dans la collection « Que sais-je ? ») ; J.-M. Durand-Gasselin, L'Ecole de Francfort, Paris, Gallimard, 2012 ; Th. W. Adorno-M. Horkheimer, Kulturindustrie, trad. fr. par E. Kaufholz, Paris, Allia, 2012 - il s'agit du chapitre consacré à l'industrie culturelle de la Dialectique de la raison, traduction française par E. Kaufholz de Dialektik de l'Aufklärung, Paris, Gallimard, 1974, dont la dernière réédition date de 2010. D'autres ouvrages récents mériteraient une analyse approfondie: G. Moutot, Langage et réification chez Adorno, Paris, PUF, 2004 et Essai sur Adorno, Paris, Payot, 2011 ; K. Genel, Autorité et émancipation. Horkheimer et la Théorie critique, Paris, Payot, 2013 ; M. Löwy, La cage d'acier. Max Weber et le marxisme weberien, Paris, Stock, 2013 ; I. Macdonald, 
P.-F. Noppen, G. Raulet (éd.), Les normes et les possibles. Héritage et perspectives de l'École de Francfort, Paris, Éditions de la Maison des Sciences de l'Homme, 2013. Toutes ces études me semblent privilégier l'inscription de la Théorie critique dans une généalogie et une problématique internes à la philosophie en tant que spécialité disciplinaire : du coup, les effets de la critique de la Kulturindustrie sur des approches « militantes » de la sphère culturelle font rarement l'objet d'une étude spécifique.

2. Nous utiliserons toujours le titre allemand de l'ouvrage d'Adorno et Horkheimer. Le titre français - Dialectique de la raison - est en effet fourvoyant. L'Aufklärung correspond en Allemand aux Lumières, tant comme mouvement historico-culturel que comme processus du «fairelumière » dans les esprits (cf. Kant, Was ist Aufklärung ?). Sa traduction par « raison » finit par effacer l'allusion aux Lumières historiques et surtout aux apories du concept bourgeois d'émancipation, lequel n'est pas immédiatement impliqué par le concept de "raison ». Que les auteurs de la Dialektik aient voulu évoquer les Lumières, et non simplement la "raison », est révélé par le fait qu'ils n'ont pas utilisé le mot Vernunft, lequel, dans le langage de la philosophie classique allemande, correspond invariablement à la « raison » en tant que faculté de l'esprit et forme de la pensée. En attribuant une simple «critique de la raison » à l'Ecole de Francfort, au lieu de la critique du concept de raison qui a fini par s'affirmer dans le processus des Lumières, on finit par effacer les marques historiques de son propos et par le réduire à un heideggerianisme honteux.

3. A l'exception notable de P.-E. Dauzat dans la Postface écrite pour la nouvelle édition revue et augmentée de G. Steiner, Langage et silence, Paris, Les belles lettres, 2010. Cependant, la problématique de l'industrie culturelle et des formes de la culture de masse n'y fait pas l'objet d'un traitement spécifique.

4. N. Poulantzas, «La crise des partis », entretien recueilli dans Id., Répères, Paris, F. Maspero, 1979, p. 178-179.

5. H.-M. Enzensberger, « Le triomphe du Bild-Zeitung, ou la catastrophe de la liberté de la presse » (1983), in Id., Mittelmass und Wahn, Frankfurt a. M., Suhrkamp, 1988, traduction française par P. Gallissaires et R. Simon, Médiocrité et folie, Paris, Gallimard, 1991, p. 90-91.

6. Ibid., p. 92-93.

7. Ibid., p. 93.

8. Ibid., p. 94-95.

9. Ibid., p. 91-92.

10. H.-M. Enzensberger, «Eloge de l'analphabétisme » (1985), dans Id., Médiocrité et folie, op. cit., p. 78-79.

11. H.-M. Enzensberger, «Le façonnement industriel de l'esprit» (1962), dans Id., Einzelheiten, Frankfurt a. M., Suhrkamp, 1962 ; traduction française par B. Lortholary, Culture ou mise en condition? (1965), Paris, Les Belles Lettres, 2012, p. 15-16.

12. Ibid., p. 22.

13. Ibid.

14. Ibid., p. 19-20.

15. M. Horkheimer-Th. W. Adorno, La dialectique de la raison, op. cit., p. 129.

16. Ibid., p. 130.

17. Ibid.

18. Ibid.

19. Ibid., p. 131.

20. Ibid., p. 130.

21. Ibid., p. 135.

22. Ibid., p. 139-140.

23. Ibid., p. 140. 
24. Le débat italien sur l'industrie culturelle et la fonction intellectuelle aboutira à des positions fort proches de celles d'Enzensberger, en particulier celles de Franco Fortini.

25. Fr. Jameson, Postmodernism (1991), Duke University Press, traduction française par Fl. Nevoltry, Le postmodernisme, ou la logique culturelle du capitalisme tardif, Paris, Editions de l'Ecole Nationale Supérieure de Beaux-Arts, 2007, 2012, p. 16.

26. Ibid.

27. Ibid., p. 33.

28. Ibid., p. 34.

29. Ibid., p. 34-35.

30. Ibid., p. 37.

31. F. Fortini, «Introduzione », in F. Fortini-L. Binni, Il movimento surrealista. Gli autori, le opere, $i$ testi, Milan, Garzanti, 1959, 1977, 1991, p. 21.

32. Ibid., p. 22-23.

33. F. Jameson, Le postmodernisme, op. cit., p. 37.

34. Ibid., p. 422-423.

35. Ibid., p. 423.

36. Ibid., p. 439.

37. Ibid., p. 426.

38. Ibid., p. 426-427. En Italie, la notion forgée par E. Bloch est traduite habituellement par "contemporanéité du non-contemporain », ce qui accentue l'aspect historique du phénomène par rapport au sens physico-cosmologique que suggèrent la simultanéité et le synchronisme (mais pour Bloch l'histoire humaine et la cosmologie sont souvent superposables).

39. Ibid., p. 429-430.

40. G. Steiner, « Les archives de l'Eden » (1981), dans Id., Passions impunies, Paris, Gallimard, 1997, p. 288-289.

41. Selon F. Fortini : "Il n'y pas de culture de masse, il n'y a que des formes hautement différenciées dans le cadre d'instruments qui sont, eux, réellement de masse. Ces instruments vont de l'école (...) à l'édition (livres, journaux, revues hebdomadaires, etc.), à la publicité, qui est une puissante forme de culture de masse, et naturellement à toutes les formes de l'audiovisuel » (F. Fortini, «Contro lo snobismo di massa » (1989), dans Id., Un dialogo ininterrotto. Interviste 1952-1994, Turin, Bollati Boringhieri, 2003, p. 552).

42. F. Fortini, «Contro lo snobismo di massa », op. cit., p. 555.

\section{RÉSUMÉS}

L'article traite de la réception récente de la Théorie Critique en France et du peu d'attention que cette réception consacre à la problématique de l'industrie culturelle développée dans la Dialektik der Aufklarung. Les prolongements de cette problématique par les courants politiques italiens et allemands des années 1960, puis par la théorie du postmodernisme de Fredric Jameson permettent d'esquisser une histoire différente de la Théorie Critique.

L'articolo tratta della ricezione francese recente della Teoria Critica e della scarsa attenzione che essa ha dedicato alla problematica dell'industria culturale sviluppata nella Dialektik der Aufklarung. La continuazione di questa problematica nelle correnti politiche italiane e tedesche 
degli anni 1960 e poi nella teoria del postmoderno di Fredric Jameson permettono di disegnare una storia alternativa della Teoria Critica.

\section{INDEX}

Index géographique : Europe occidentale, Etats-Unis

Thèmes : esthétique, théorie critique, marxisme, philosophie allemande

Mots-clés : Kulturindustrie, modernisme, postmodernisme, Adorno, Enzensberger, Fortini, Jameson Frederic

Index chronologique : XXe siècle, années 1940-1990

\section{AUTEUR}

\section{ANDREA CAVAZZINI}

Membre du GRM et de l'association « Louis Althusser », travaille depuis plusieurs années sur l'histoire du communisme et du marxisme au XXe siècle. Il est post-doctorant à l'Université de Liège.

cavazz.a@tin.it 